\title{
Effects of density on the vital rates of a modular seaweed
}

\author{
R. M. Viejo*, P. Åberg \\ Department of Marine Botany, Göteborg University, Box 461, 40530 Göteborg, Sweden
}

\begin{abstract}
The effects of density on the vital rates of the modular seaweed Ascophyllum nodosum (L.) Le Jol. were investigated in 2 areas of the northern Atlantic Ocean: the Isle of Man, in the Irish Sea, and Tjärnö, on the Swedish west coast. The densities of plants (genets) were manipulated in the field. The impact of density on survival, growth and reproduction of plants $>2 \mathrm{~cm}$ was estimated over 1 yr. Percentage survival of $A$. nodosum was high and apparently density-independent. This result is in accordance with other studies in land and marine systems where low mortality after establishment appears common and overpopulation is avoided by a balance in module density. The growth of $A$. nodosum was negatively density-dependent. The response of the modules (shoots) within plants was asymmetrical. Furthermore, the inception of new shoots was enhanced at low densities on the Isle of Man. Apart from intraspecific competition, other density-dependent processes affected the performance of the alga: the probability of breakage to smaller sizes increased with density in the Swedish area. As a result, the impact of density on the net plant growth was more patent at Tjärnö than on the Isle of Man. In relation to reproduction, the results of this study suggest a positive effect of density on the annual reproductive effort of the alga. Nevertheless, the manipulation was carried out after the initiation of reproductive structures. Increasing density clearly reduced plant growth, and reproduction is size-dependent in A. nodosum. This indicates that, in successive reproductive periods, reproduction may be negatively affected by density. In contrast to the results of another previous work, our study shows a negative impact of density on the net growth of $A$. nodosum and indicates the importance of module length structure in the demographical processes of the species. Not only the effect of density but also the significance of density dependence in the dynamics of the species probably vary in these areas with very different physical domains.
\end{abstract}

KEY WORDS: Ascophyllum nodosum · Demography · Growth · Intraspecific competition · Rocky shores

Resale or republication not permitted without written consent of the publisher

\section{INTRODUCTION}

Intraspecific interactions have been widely investigated in terrestrial plants, although the investigations have focused mainly on agricultural and experimental populations rather than on natural stands (Harper 1977, Antonovics \& Levin 1980, Schmitt et al. 1986, Schmitt et al. 1987, Rice 1990, Jurik 1991, Yastrebov 1996). Most of these studies have shown that density has a negative impact on survival, growth and repro-

*Present address: Unidad de Ecología, Departamento de Biología de Organismos y Sistemas, Universidad de Oviedo, 33071 Asturias, Spain. E-mail: rmviejo@correo.uniovi.es ductive output of the individual plants. Competition is often asymmetrical, i.e., initial differences in the size of plants (due to genetic differences, timing of recruitment or differences in the microenvironment) are magnified by intraspecific interactions, small plants being more affected than larger ones and size inequality increasing at high densities (Weiner \& Thomas 1986, Rice 1990). Light competition appears to be critical in establishing this pattern of dominant and suppressed individuals, with large plants shading small ones (Schmitt et al. 1986).

The modular character of terrestrial plants and its importance in population dynamics has also been extensively acknowledged (Sprugel et al. 1991 and 
references therein). Modules are repetitive components of plants (genets), which may in some degree behave as physiologically independent units (Schmid 1990). Expressions of plant modularity are the clonal growth of herbaceous species, where each genet commonly comprises numerous ramets, and the branch architecture of trees. Very few studies in terrestrial systems, however, have investigated how competition between genets is related to interactions between their modules (de Kroon et al. 1992, Sorrensen-Cothern et al. 1993). Many marine macroalgae also have a modular construction, but the dynamics of modules are largely unexplored (Lazo \& Chapman 1998).

In marine systems, large, almost monospecific aggregations of macroalgae are common in the intertidal and subtidal levels of boreal and temperate rocky shores (Moore \& Seed 1985). In these monospecific stands, competition can be intense and theoretically less complex than in terrestrial systems, simply because of the absence of a below-ground component (algae having no roots). However, conflicting results have been obtained from studies of intraspecific interactions in seaweeds, resulting in a debate over the relevance of terrestrial-based models in algal ecology (see the contrasting views of Schiel \& Choat 1980, Cousens \& Hutchings 1983, Schiel 1985).

As Cousens \& Hutchings (1983) pointed out, clarification of density-dependent effects in seaweeds requires the use of manipulative experiments because this is the only way to show that density is the cause of the effects. Considerable progress has recently been made with such experiments (Reed 1990, Ang \& De Wreede 1992, Kendrik 1994, Creed et al. 1996, Creed et al. 1998, Lazo \& Chapman 1998). However, observational studies are also valuable especially as a first attempt to investigate processes correlated with density. Results from both manipulative and observational studies suggest that the algal responses to density are in many cases similar to those observed in terrestrial plants. Self-thinning or density-dependent mortality is common in macroalgal stands (Schiel \& Choat 1980, Dean et al. 1989, Kendrick 1994, Creed et al. 1996) as it is in terrestrial systems (Harper 1977, Westoby \& Howell 1986, Schmitt et al. 1987). Algal individuals often have lower growth rates in crowded stands, and the effects are more dramatic in small plants (Reed 1990, Ang \& De Wreede 1992, Creed et al. 1998). Changes in the morphology of algae have likewise been reported, with plants at high density being more elongated or less ramified than at low density (Reed 1990, Holbrook et al. 1991, Sjøtun \& Frediksen 1995, Andrew \& Viejo 1998), a response similar to that observed in terrestrial plants (Harper 1977, Silvertown \& Lovett Doust 1993, Hutchings \& de Kroon 1994). However, in contrast to these studies and those on terres- trial plants, positive effects of density on the survival, growth and reproduction of algae have also been documented (Hruby \& Norton 1979, Schiel \& Choat 1980, Schiel 1985, Ang \& De Wreede 1992, Bertness \& Leonard 1997, Lazo \& Chapman 1998). As Dean et al. (1989) pointed out, the diverse intraspecific effects of density on seaweeds may reflect not only differences between species but also interactions with the physical environment. For example, for seaweeds growing in intertidal habitats, crowding can confer protection against desiccation or heat stress, increasing collective survival and growth (Hruby \& Norton 1979, Hay 1981, Ang \& De Wreede 1992) whereas kelp populations in deep water undergo self-thinning, probably as a result of light limitation (Dean et al. 1989). The manipulation of natural stands in different physical environments may thus provide new insights into the patterns and mechanisms of density-dependent regulation in marine plants.

It can be more difficult to detect significant effects of a given factor in experiments carried out in natural populations than in other manipulative experiments in, e.g., greenhouses or experimental field plots. The main reason is the natural variations of factors not explicitly included in the experiment, which increase the residual variance (i.e., among replicates) in an analysis of variance. However, the strength of manipulative experiments in natural populations is that, when significant effects are found, the generality and predictive power are much higher than for other types of experiments. For perennial species, experiments on intraspecific competition in natural populations have been scarce and mostly restricted to manipulations where the density of established plants has been decreased (e.g., Fowler 1986, Fowler 1995, Creed et al. 1996, but see Shaw 1987). For obvious reasons it would be very difficult to increase the density of plants in many species, e.g., trees. However, for some organism groups such as intertidal seaweeds, it may be feasible to increase densities in natural stands.

In this study we investigated how stand plant density influenced the vital rates (mortality, growth and reproductive output) of the perennial brown alga Ascophyllum nodosum (L.) Le Jol., a species that commonly dominates the intertidal zone of rocky shores of the northern Atlantic Ocean. The experiment was carried out in natural populations of 2 areas that have very different physical conditions in order to investigate the variability in the sign or intensity of the density-dependent regulation. Manipulations were both increases and decreases in density of adult plants (genets). In a previous work we investigated the effect of density and other biological factors on the mortality of juvenile stages of this species (Viejo et al. 1999). We focused here on the effects of stand density on adult plants. The 
experiment was designed to investigate effects of genet density on the survival, growth and reproductive output of genets as well as the recruitment and growth of modules (shoots). In relation to the growth of modules, we tested the hypothesis that the effects of density are asymmetrical, with the growth of shortest shoots being more affected by increases in genet density than the longest shoots.

\section{MATERIALS AND METHODS}

Study sites. The experiment was carried out in 2 areas of the north-eastern Atlantic Ocean: the Langness shore on the Isle of Man, Irish Sea $\left(54^{\circ} 05^{\prime} \mathrm{N}\right.$, $4^{\circ} 37^{\prime} \mathrm{W}$ ), and small islands in the archipelago close to Tjärnö Marine Biological Laboratory on the Swedish west coast $\left(58^{\circ} 54^{\prime} \mathrm{N}, 11^{\circ} 07^{\prime} \mathrm{E}\right)$, from September 1997 to September 1998. The distance between these 2 areas (hereafter referred to as Isle of Man and Tjärnö) is approximately $1000 \mathrm{~km}$ and the environmental conditions are very different. At Tjärnö the tidal range is as small as $0.3 \mathrm{~m}$, though the water level can vary up to $2 \mathrm{~m}$ through the year because of winds and changes in atmospheric pressure (Johannesson 1989). Ice occurs in about $25 \%$ of the years and the ice cover has been found to be an important source of mortality for AsCophyllum nodosum (Åberg 1992a). Large variations in salinity are also common in this area and the mean salinity is $24 \%$. The environment at Tjärnö can be described as stochastically variable (Åberg 1992b). On the Isle of Man environmental conditions are more predictable, with no ice, stable salinity (mean 34\%) and tidal ranges of about $7 \mathrm{~m}$. It has also been shown that the population growth rate is less variable on the Isle of Man than on Tjärnö (Pavia \& Åberg unpubl. data).

On the Isle of Man the vertical distribution of Ascophyllum nodosum is 2 to $3 \mathrm{~m}$ in the mid-intertidal zone of sheltered shores; on shores with moderate slopes the Ascophyllum spp. zone can be up to $100 \mathrm{~m}$ wide. At Tjärnö the vertical distribution of A. nodosum is restricted to 0.1 to $0.5 \mathrm{~m}$ below the mean water level because of the limited tidal range, and thus the width of the A. nodosum zone is usually $<0.5 \mathrm{~m}$ and rarely $>2 \mathrm{~m}$. Despite these differences, the total abundance and mean size of $A$. nodosum plants within the narrow belts at Tjärnö are similar to those in the mid-intertidal zone on the Isle of Man (Åberg \& Pavia 1997).

The field experiment. The natural densities of plants (genets) of Ascophyllum nodosum were manipulated in the field. Genets were distinguished following the recommendations of Åberg (1989). Juvenile individuals $(<2 \mathrm{~cm}$ in length) were not considered in this study. On the Isle of Man 3 experimental densities ('high', 'mid' and 'low') were used. Natural densities were increased by transplantation of individuals and reduced by cutting plants from the holdfast. The thinning was accomplished taking into account the distance between plants; when 2 plants were close neighbours, 1 of them was removed. For the transplantation, pieces of rock with attached algae were chipped off from the limestone platform and cemented onto clearings in the experimental plots. Every effort was made to avoid contact between the plants and the concrete. At Tjärnö only 2 densities (mid and low) were achieved by thinning natural densities. It was not possible to increase the densities because of the hardness of the granite rock and the reduced tidal amplitude, which imposed strict limits on the time for manipulation of the plants.

The experimental units consisted of $0.25 \mathrm{~m}^{2}$ plots randomly placed in the middle of the Ascophyllum nodosum belt. The dimensions of the plots were $0.5 \times$ $0.5 \mathrm{~m}$ on the Isle of Man, and $0.30 \mathrm{~m}$ vertically and $0.82 \mathrm{~m}$ horizontally at Tjärnö because of the restricted width of the A. nodosum belt. Five replicate plots were used in the mid and low density treatments on the Isle of Man and 4 in the rest of the treatments. The plots were 15 to $1000 \mathrm{~m}$ apart in both areas and they were randomly assigned to the density treatments.

Around each plot a $15 \mathrm{~cm}$ buffer zone was subjected to the same manipulation but was not sampled. The total manipulated area was thus $0.64 \mathrm{~m}^{2}$ on the Isle of Man and $0.67 \mathrm{~m}^{2}$ at Tjärnö. During the periods of submergence, bladders kept the fronds upright inside the plots. Although Ascophyllum nodosum is able to grow when emerged (see reference in Lazo \& Chapman 1998), seaweed grows mainly during periods of submergence at high tide (Lobban et al. 1985).

In each plot all the plants were mapped and the length and circumference of each plant measured served to estimate individual dry mass (see Åberg 1990 for method). The individual weights were estimated at the start and at the end of the experiment. An additional sampling was carried out at Tjärnö during May 1998. As plants were mapped, the individual growth and survival was recorded. Mortality was defined as the complete removal of a genet. Transplanted plants were used to establish the experimental densities, but they were not considered in subsequent measures. This procedure was followed to avoid the addition of transplant artefacts on the survival and growth estimations.

The initial numbers of plants (mean $\pm \mathrm{SE}$ ) in the high, mid and low densities were, respectively, $39 \pm 2,25 \pm 2$ and $10 \pm 1$ plants per $0.25 \mathrm{~m}^{2}$ on the Isle of Man, and $23 \pm 3$ and $8 \pm 1$ plants in mid and low densities at Tjärnö. These densities were within the natural range in those areas. The highest and lowest sampled densities (juveniles excluded) were, respectively, 55 and 
19 plants per $0.25 \mathrm{~m}^{2}$ on the Isle of Man, and 54 and 7 at Tjärnö (R.M.V. unpubl. data). Mean values were 19 per $0.25 \mathrm{~m}^{2}$ (76 plants per $\mathrm{m}^{2}$ ) on the Isle of Man and 24 to 25 per $0.25 \mathrm{~m}^{2}\left(99\right.$ per $\mathrm{m}^{2}$ ) at Tjärnö (Åberg \& Pavia 1997). Some transplanted plants were lost over the year. Excluding these losses, the number of plants in the high density treatment was $35 \pm 2$ per $0.25 \mathrm{~m}^{2}$ on the Isle of Man, which is the experimental density that will be considered hereafter. At the start of the experiment the estimated total dry mass per $0.25 \mathrm{~m}^{2}$ (mean \pm $\mathrm{SE}$ ) in the high, mid and low densities were, respectively, $3.24 \pm 0.42,1.29 \pm 0.32$ and $0.72 \pm 0.07 \mathrm{~kg}$ on the Isle of Man, and $1.45 \pm 0.16$ and $0.48 \pm 0.07 \mathrm{~kg}$ in the mid and low densities at Tjärnö (lost transplantations excluded). The experimental treatments differed initially in both number of plants and total dry mass per plot, without significant differences between areas (Table 1a,b). On the Isle of Man, however, the total dry masses of mid and low density plots were not significantly different (Table 1b). This was because of the smaller mean size of the plants in the mid density plots in relation to the low ones.

A plant (genet) of Ascophyllum nodosum has several primary vegetative shoots (modules) arising from a common holdfast. We investigated how recruitment and growth of modules were affected by genet density. If the effects of density were asymmetrical within plants, the growth of shortest shoots would be more affected by increases in plant density than the longest shoots. In order to test this hypothesis, the growth of several primary shoots was estimated in 3 plants (dry wt per plant $>160 \mathrm{~g}$ ) in 4 plots per density and area (i.e., a total of 12 plants per density and area). Unbroken vegetative shoots produce 1 air bladder in February of each year with the exception of the first years. The length from the apex to the youngest air bladder was measured in undamaged shoots in September 1998. These lengths were used to estimate the growth from February to September 1998, after verifying that the width of these newly formed parts of the modules did not differ between plants of different densities. The longest and shortest shoots were chosen within the plants (1 to 3 shoots per length category and plant). Mean difference in length between the long and short shoots $( \pm$ SE) was $50.2 \pm 3.0 \mathrm{~cm}, \mathrm{n}=60$ (data pooled across areas and densities). The elongation of the shoots was measured as explained above, and the mean elongation of both 'long' and 'short' shoots was calculated per plant. To investigate the effect of density on the inception of modules, the number of new shoots arising from the holdfast $(<5 \mathrm{~cm}$ long and with no air bladders) was counted in 6 plants in 4 plots per density and area (i.e., a total of 32 plants per density and area).

The effect of density on the reproductive output of Ascophyllum nodosum plants was investigated at Tjärnö in May 1998. In Sweden A. nodosum is reproductive during a short period in April or May. The reproductive structures, or receptacles, are shed soon after the reproductive period. New receptacles are initiated during the summer. The receptacles start to grow from lateral pits along the shoots, but vegetative laterals can also grow from these pits. Changes in plant density may affect the ratio of reproductive to vegetative laterals in the plants. However, since receptacles

Table 1. Analyses of variance for the number of plants (a) and total dry mass (b) in experimental treatments and areas. For each dependent variable 2 analyses of variance were carried out, 1 with mid and low densities in both areas (Isle of Man and Tjärnö) and the other with 3 densities on the Isle of Man. A posteriori comparisons between means after significant $F$ tests using StudentNewman-Keuls (SNK) tests are also shown

\begin{tabular}{|c|c|c|c|c|c|c|c|c|c|}
\hline \multirow{2}{*}{$\begin{array}{l}\text { a) Plant number } \\
\text { Source }\end{array}$} & \multicolumn{4}{|c|}{$\begin{array}{l}\text { Isle of Man-Tjärnö } \\
\text { (mid and low density) }\end{array}$} & \multicolumn{5}{|c|}{$\begin{array}{c}\text { Isle of Man } \\
\text { (high, mid and low density) }\end{array}$} \\
\hline & $\mathrm{df}$ & Mean Squares & $F$ & $\mathrm{p}$ & Source & $\mathrm{df}$ & Mean Squares & $F$ & $\mathrm{p}$ \\
\hline Density & 1 & 997.556 & 65.78 & 0.000 & Density & 2 & 728.975 & 51.55 & 0.000 \\
\hline Area & 1 & 20.544 & 1.36 & 0.264 & Residual & 11 & 14.141 & & \\
\hline Density $\times$ area & 1 & 0.044 & 0.00 & 0.958 & & & & & \\
\hline Residual & 14 & 15.164 & & & \multirow{2}{*}{\multicolumn{5}{|c|}{$\begin{array}{l}\text { SNK test: high density }>\text { mid }>\text { low } \\
\text { Isle of Man } \\
\text { (high, mid and low density) }\end{array}$}} \\
\hline \multicolumn{2}{|l|}{ b) Total biomass } & \multicolumn{2}{|c|}{$\begin{array}{l}\text { Isle of Man-Tjärnö* } \\
\text { (mid and low density) }\end{array}$} & \multirow[b]{2}{*}{$\mathrm{p}$} & & & & & \\
\hline Source & $\mathrm{df}$ & Mean Squares & $F$ & & Source & $\mathrm{df}$ & Mean Squares & $F$ & $\mathrm{p}$ \\
\hline Density & 1 & 0.533 & 17.97 & 0.001 & Density & 2 & 7.589 & 19.63 & 0.000 \\
\hline Area & 1 & 0.009 & 0.31 & 0.590 & Residual & 11 & 0.387 & & \\
\hline Density $\times$ area & 1 & 0.085 & 2.85 & 0.114 & & & & & \\
\hline Residual & 14 & 0.030 & & & & & & & \\
\hline
\end{tabular}


are initiated during summer and the experiment was started in September, crowding should have affected the size of the receptacles more than their number. To test this hypothesis, the receptacles of 2 shoots per plant were collected in 7 plants per density (randomly chosen among the plots). A. nodosum is a dioecious species but sex was not included as a factor in the experiment. Receptacles per shoot were counted and the total fresh weight of receptacles was measured to estimate the mean fresh weight per receptacle. In $A$. nodosum there is a very strong relation between fresh weight and dry weight. The fresh and dry weights were measured on whole plants in a number of populations and sampling dates in Sweden, and the relation was highly significant (linear regression, $\mathrm{p}<0.0001$, $\mathrm{n}=495$ ) with $\mathrm{R}^{2}=0.97$ (P.Å. unpubl. data).

Statistical procedures. Percentage survival and several dependent variables related to the growth of Ascophyllum nodosum were analysed using, in each case, 2 analyses of variance: (1) a 2-way analysis of variance with density (mid and low) and area (Tjärnö and Isle of Man) as fixed and orthogonal factors; and (2) a 1-way analysis of variance, to compare the 3 experimental densities on the Isle of Man. Because the number of replicated plots differed between density treatments and areas (see above), type III sum of squares was used (see comments in Shaw \& MitchellOlds 1993 for analysis of unbalanced data). Before the analysis of variance, data were tested for homogeneity of variances with Cochran's test (Winer et al. 1991). Differences between means after significant $F$ tests were analysed by Student-Newman-Keuls tests. For the analysis of the growth of shoots a random factor, plot, was incorporated into the design, nested within the interaction between density and area.

Furthermore, the final length and dry mass of individual plants was compared between densities within each area (Isle of Man and Tjärnö) with analysis of covariance. Initial length and initial dry mass were used as respective covariates. Data from different plots were pooled. Dry mass values were log transformed. The homogeneity of slopes was tested.

All data analysis were carried out using SuperANOVA 1.11 for Macintosh computers (SAS Institute, Cary, NY, USA).

\section{RESULTS}

Percentage survival of $1 \mathrm{yr}$ after the density manipulation was high (mean \pm SE $93.74 \pm 0.30 \%, n=22$ ), with no significant differences between either areas $(F=0.054, \mathrm{p}=0.473)$ or densities $\left(F_{1,14}=0.02, \mathrm{p}=0.883\right.$ for mid and low densities in both areas; $F_{2,11}=0.90, p=$ 0.435 , for the 3 densities on the Isle of Man).
Table 2. Analysis of variance for the relative change in total dry mass of the plots (proportion of final to initial mass) in the mid and low densities in both areas. Data were log transformed to homogenize variances. Student-Newman-Keuls (SNK) test for a posteriori comparisons between means are also shown

\begin{tabular}{|c|c|c|c|c|}
\hline Source & $\mathrm{df}$ & MS & $F$ & $\mathrm{p}$ \\
\hline Density & 1 & 0.183 & 16.89 & 0.001 \\
\hline Area & 1 & 0.013 & 1.21 & 0.290 \\
\hline Density $\times$ area & 1 & 0.094 & 8.69 & 0.011 \\
\hline Residual & 14 & 0.011 & & \\
\hline \multicolumn{5}{|c|}{$\begin{array}{l}\text { SNK test }{ }^{\mathrm{a}} \text { : low Tjärnö low Isle of Man } \sim \text { mid Isle of Man } \\
>\text { mid Tjärnö }\end{array}$} \\
\hline \multicolumn{5}{|c|}{$\begin{array}{l}{ }^{\mathrm{a}}>\text { significantly higher at } \mathrm{p}=0.05 ; \sim \text { not significantly dif- } \\
\text { ferent at } \mathrm{p}=0.05\end{array}$} \\
\hline
\end{tabular}

The relative change in the total dry mass of the plots (as a proportion of final to initial mass) was, however, affected by the combination of density and area (Table 2, Fig. 1). At Tjärnö the changes were more dramatic: the total mass in the mid density plots decreased over the experimental year whereas a substantial increase was observed at low density (Table 2, Fig. 1). On the Isle of Man there were no reductions in the total mass at any density, but the relative increase was lower at high density $\left(F_{2,11}=6.84, \mathrm{p}=0.012\right.$, Fig. 1$)$. The changes in the total dry mass of the plots were exclusively the result of the net growth of individual plants, excluding mortality (only surviving plants were

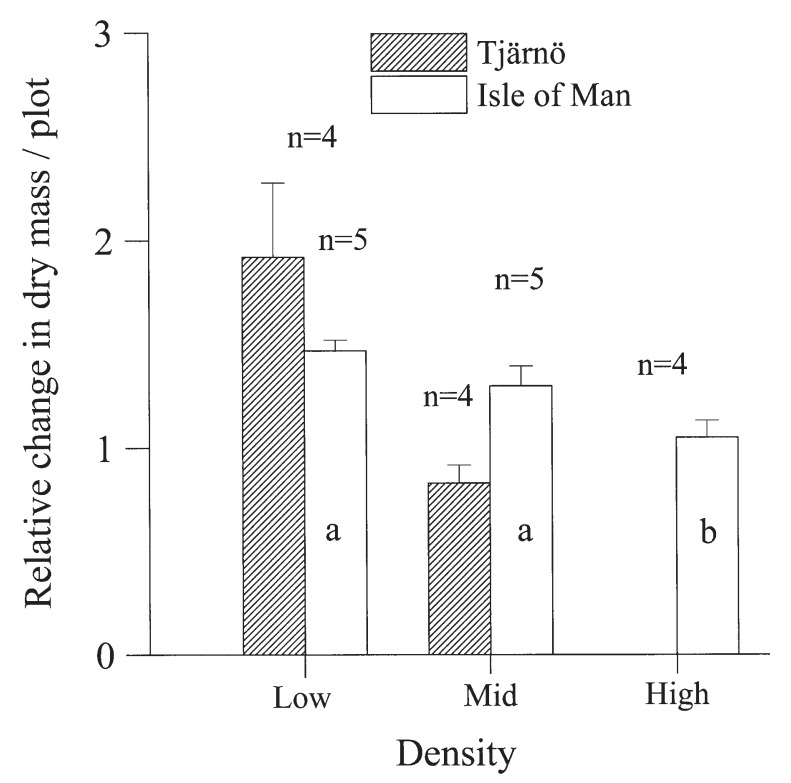

Fig. 1. Relative change in total dry mass of the plots (proportion of final to initial mass) in the different densities and areas. Mean \pm SE values are shown. Letters indicate the different mean groups in the SNK test at $\mathrm{p}<0.05$ for the 3 densities on the Isle of Man 
considered for these calculations). However, when the final dry mass of the individuals was compared between densities, no significant differences were found either at Tjärnö (analysis of covariance, $F_{1,110}=2.24$, $\mathrm{p}=0.138$ ) or on the Isle of Man (analysis of covariance, $\left.F_{2,202}=0.04, p=0.961\right)$. Furthermore, there was no evidence of a differential effect of density related to the size of the plants. The slopes of the regressions were similar between densities (analysis of covariance, nonsignificant interaction between initial mass and density: $F_{1,110}=0.29, \mathrm{p}=0.592$ for plants at Tjärnö; $F_{2,202}=$ $0.14, p=0.872$ for plants on Isle of Man). When the total length instead of the dry mass of the individual plants was compared between densities, the results were similar: no significant differences between densities or size-dependent effects of density were detected.

Some plants lost weight over the experimental year because of frond breakage. The decline in the total mass of the mid density plots at Tjärnö (see Fig. 1) was certainly the result of individual losses. In this area, the percentage of plants with weight loss was apparently higher at mid than at low density, whereas no differences were observed on the Isle of Man (Fig. 2). The differences, however, were only statistically significant at Tjärnö during the period from September 1997 to May $1998\left(F_{1,6}=23.58, \mathrm{p}=0.003\right)$. The probability of breakage increased with plant length and this increase was more pronounced at Tjärnö than on the Isle of Man (Fig. 3).

The elongation measurements estimated the growth of the shoots, excluding losses due to breakages. The effect of density on shoot elongation differed between long and short shoots. There were no differences in the

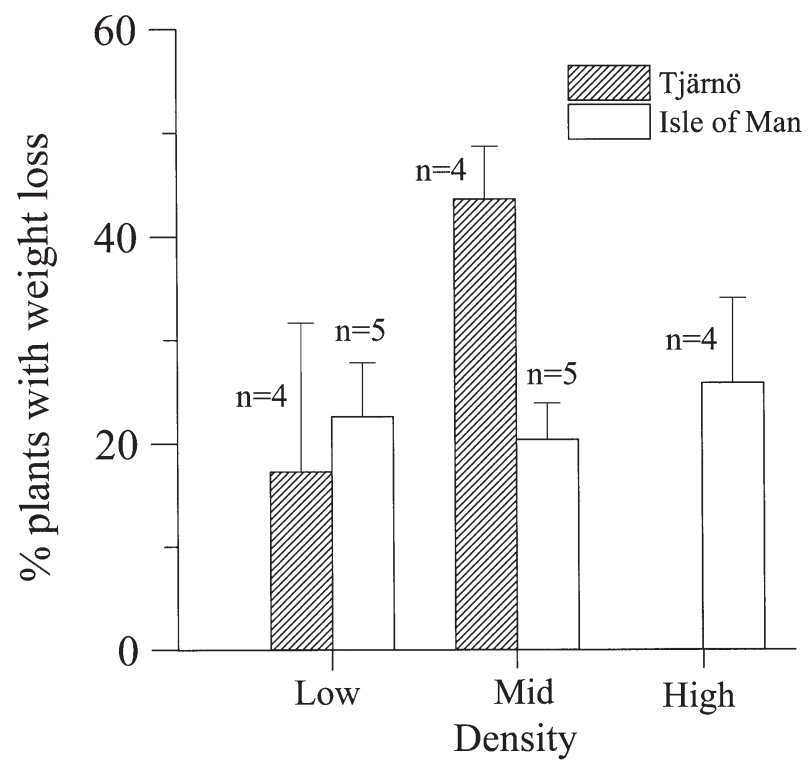

Fig. 2. Percentage of plants with weight losses in the different densities and areas. Mean $\pm \mathrm{SE}$ values are shown

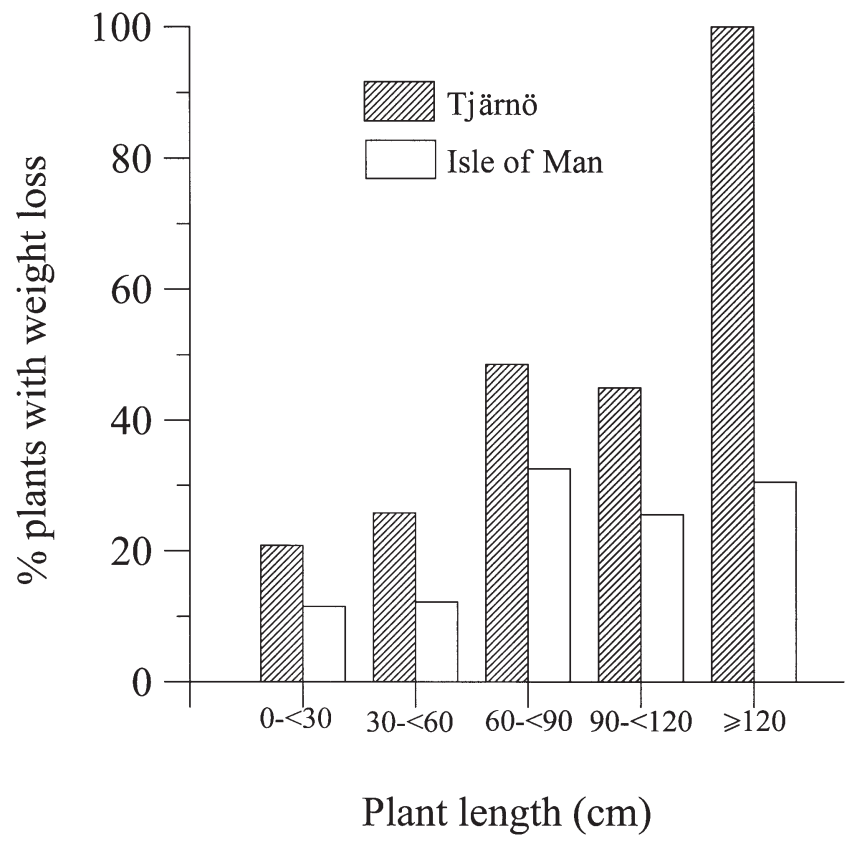

Fig. 3. Percentage of plants with weight loss in relation to the total length of plants on both areas (plants pooled across plots and densities)

elongation of long shoots between either areas $\left(F_{1,12}=\right.$ $2.56, \mathrm{p}=0.135)$ or densities $\left(F_{1,12}=1.03, \mathrm{p}=0.330\right.$ considering 2 densities and both areas; $F_{2,9}=0.29, \mathrm{p}=$ 0.753 , considering the 3 densities on the Isle of Man) (Fig. 4). However, the elongation of the short shoots was negatively affected by density in both areas (Table 3, Fig. 4). On the Isle of Man a progressive decrease was observed from low to high density $\left(F_{2,29}=26.47, \mathrm{p}<0.0001\right.$, Fig. 4$)$. Short shoots grew more than long ones in plants at low density, whereas the opposite trend was observed in plants growing at mid density and especially at high density (Fig. 4). Moreover, on the Isle of Man plants growing at low density had a higher number of new shoots $(<5 \mathrm{~cm}$ length) $\left(F_{2,68}=30.92, \mathrm{p}<0.0001\right.$, Fig. 5$)$ whereas the inception of new shoots did not differ between mid and low densities at any area (Table 4, Fig. 5).

Density did not affect the mean weight of reproductive structures in plants growing at Tjärnö. The mean fresh weight per receptacle was similar in plants growing at mid and low densities $\left(F_{1,12}=0.15, \mathrm{p}=0.709\right.$; mean \pm SE $0.301 \pm 0.027 \mathrm{~g}, \mathrm{n}=28$ ).

\section{DISCUSSION}

Our results conform to those of many terrestrial and marine studies, in which plants growing at higher densities experience reductions in the net growth (e.g., Black 1974, Harper 1977, Antonovics \& Levin 1980, 


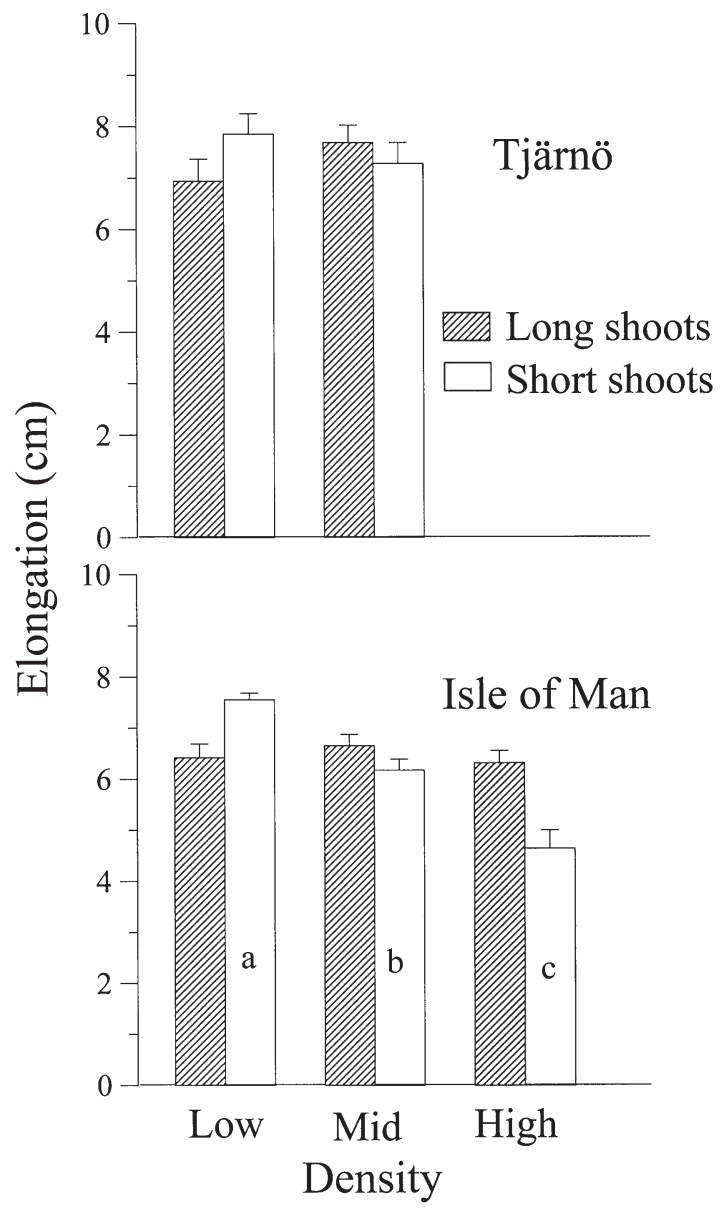

Fig. 4. Elongation of 'long' and 'short' shoots in the different densities and areas. Data pooled across plots. Mean \pm SE values are shown, $\mathrm{n}=12$. Letters indicate the different mean groups on the SNK test at $\mathrm{p}<0.05$ for the 3 densities on the Isle of Man

Reed 1990, Ang \& De Wreede 1992, Creed et al. 1996, Creed et al. 1998). Marine algae are frequently subject to erosion from waves, ice or herbivores. The results of this study indicate that both growth and plant breakage are density-dependent in Ascophyllum nodosum.

This seaweed is a modular organism with tightly aggregated units (primary shoots) arising from a common holdfast. We observed a size-dependent response of the modules to increases in plant density, the growth of short shoots being negatively affected but not the long ones. Furthermore, on the Isle of Man low density promoted the formation of new shoots. In this sense, Ascophyllum nodosum resembles a terrestrial clonal plant with closely aggregated modules, i.e., with 'phalanx strategy' (Lovett Doust 1981), where shoots within the same genet can be subject to high interference and the control of module density may be regulated by their birth rate (Schmid \& Harper 1985). The asymmetrical response of shoots to plant density is related to a
Table 3. Analysis of variance for the elongation of 'short' shoots considering mid and low density in both areas

\begin{tabular}{|lcrrr|}
\hline Source & df & MS & \multicolumn{1}{c|}{$F$} & $\mathrm{p}$ \\
\hline Density & 1 & 11.530 & 5.05 & 0.044 \\
Area & 1 & 5.968 & 2.61 & 0.132 \\
Density $\times$ area & 1 & 2.011 & 0.88 & 0.367 \\
Plot (density $\times$ area) & 12 & 2.284 & 2.23 & 0.040 \\
Residual & $28^{\mathrm{a}}$ & 1.025 & & \\
& & & \\
a Four missing replicates were replaced by the mean of the \\
corresponding plot, and 4 df was subtracted from residual \\
\hline
\end{tabular}

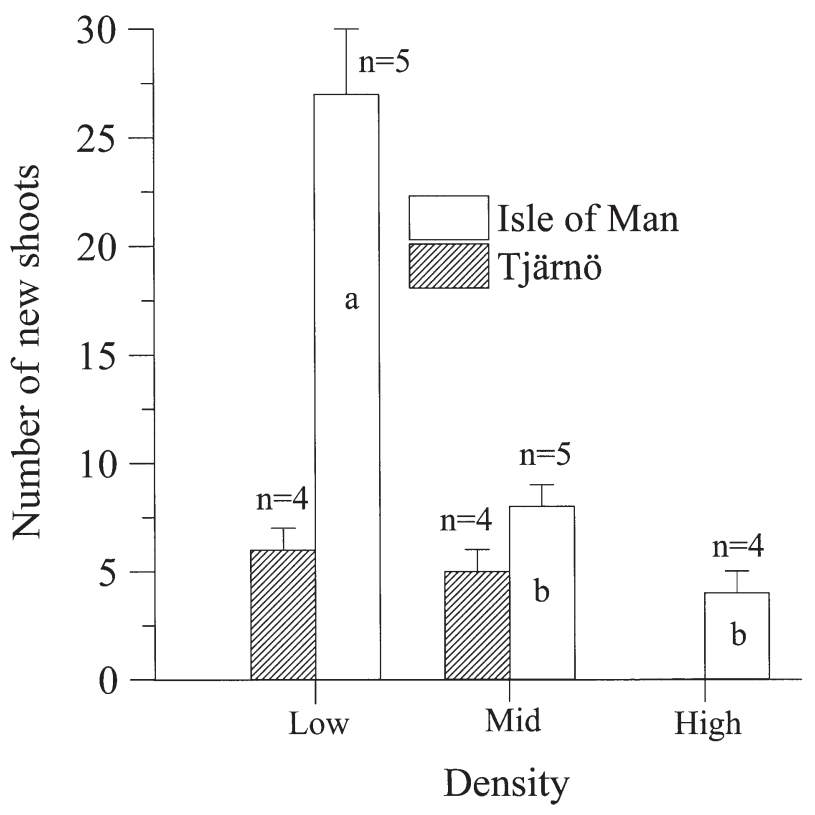

Fig. 5. Number of new shoots $(<5 \mathrm{~cm}$ length) per plant in the different densities and areas. Data from different plots were pooled. Mean $\pm \mathrm{SE}$ values are shown, $\mathrm{n}=24$. Letters indicate the different mean groups on the SNK test at $\mathrm{p}<0.05$ for the 3 densities on the Isle of Man

Table 4. Analysis of variance for the number of new shoots per plant in the mid and low densities at both areas. SNK tests for a posteriori comparisons between means are also shown

\begin{tabular}{|c|c|c|c|c|}
\hline Source & $\mathrm{df}$ & MS & $F$ & $\mathrm{p}$ \\
\hline Density & 1 & 2100.033 & 17.53 & 0.001 \\
\hline Area & 1 & 3344.939 & 27.91 & 0.000 \\
\hline Density $\times$ area & 1 & 1900.494 & 15.86 & 0.002 \\
\hline Plot (density $\times$ area) & 12 & 119.829 & 1.41 & 0.182 \\
\hline Residual & $78^{a}$ & 85.273 & & \\
\hline \multicolumn{5}{|c|}{$\begin{array}{l}\text { SNK test }{ }^{\text {b }} \text { : mid Tjärnö } \sim \text { low Tjärnö } \sim \text { mid Isle of Man }< \\
\text { low Isle of Man }\end{array}$} \\
\hline \multicolumn{5}{|c|}{$\begin{array}{l}{ }^{a} \text { One missing replicate was replaced by the mean of the cor- } \\
\text { respondent plot, and } 1 \mathrm{df} \text { was subtracted from residual } \\
\mathrm{b}_{>}>\text {significantly higher at } \mathrm{p}=0.05 ; \sim \text { not significantly dif- } \\
\text { ferent at } \mathrm{p}=0.05\end{array}$} \\
\hline
\end{tabular}


differential access to the resource and to the functional independence of modules. Asymmetrical competition between modules was also observed in terrestrial clonal plants when genet density was manipulated (de Kroon et al. 1992).

Light is often cited as a key factor influencing growth and survival in both terrestrial and marine systems (Schmitt et al. 1986, Dean et al. 1989, Reed 1990, Jurik 1991, Creed et al. 1998, Sjøtun et al. 1998). In Ascophyllum nodosum stands, it can actually be an important factor determining the suppression of short shoots and the regulation of shoot inception, as the irradiance levels decrease abruptly under a canopy of A. nodosum (Cousens 1985).

Since the effect of density was 1 -sided within plants, we also expected asymmetrical responses among plants, with the growth of small plants being affected more than that of larger ones by increases in density. This phenomenon of dominance and suppression has been observed in other seaweed species (Reed 1990, Ang \& De Wreede 1992, Creed et al. 1998), but our results did not support the hypothesis. It may be argued that the temporal scale of the experiment was too short to show any differential growth among plants. However, 2 aspects of the experiment may explain this result per se. First, the smaller size classes, the most likely to be affected by asymmetrical competition, were scarcely represented in this study, as the juvenile stages were not considered and adult plants of $<5 \mathrm{~g}$ were rare in the experimental plots. Second, other density-dependent processes affected the performance of the alga, increasing the risk of breakage to smaller sizes. Large (longer) plants broke more frequently, probably because they are more vulnerable to wave action (Gaylord et al. 1994) and they can be more exposed to desiccation stress during low water than plants growing beneath the canopy (see Ang 1991). The breakages of large plants may mask the dominance and suppression in plant growth.

As mentioned above, density also affected plant abrasion. In the Swedish area, plants at mid density suffered more risk for abrasion than plants at low density. A possible explanation for this trend is the increase of grazing damage in dense stands. It has been shown that the relative abundance of herbivores living on several species of seaweeds is higher in aggregated than in isolated plants (Black 1974, Gunnill 1982, Reed 1990). Grazing damage may cause tissue loss indirectly by increasing the susceptibility to breakage and dislodgment (see Black 1974). In fact, a high percentage of Ascophyllum nodosum plants sampled at Tjärnö (up to $30 \%$ ) had a broken frond where there was a grazing mark (R.M.V. unpubl. data). The indirect effects of grazers at higher densities may be more patent at Tjärnö than on the Isle of Man, as the physical conditions are more variable and harsher in the Swedish area. There, ice scouring in winter may cause breakage of plants to smaller sizes (Åberg 1992a). Moreover, the A. nodosum zone can be exposed to air during several consecutive days during periods of high atmospheric pressure in spring and summer (R.M.V. pers. obs.).

Increased grazing in dense stands may also explain a reduction in growth in undamaged annual shoots, though competition for light was probably the predominant process. Pavia et al. (1999) showed that there is a trade-off between phlorotannin content and annual growth in Ascophyllum nodosum. They further showed that the chemical defence is inducible by the gastropod grazer Littorina obtusata (Pavia \& Toth 2000). Thus, if this grazer is more common in dense stands, it may induce higher concentrations of phlorotannins, which results in lower growth rates of shoots.

Our results clearly show a negative effect of density on the net growth of Ascophyllum nodosum, by affecting both shoot elongation and risk of abrasion. The consequences for reproduction are more difficult to assess with the present data and conclusions can only be tentative. No differences between densities were observed in the average mass per receptacle. Since receptacles are initiated during summer (Åberg 1996) and the experiment started in September, the density manipulation should not have affected the number of receptacles arising from the laterals of shoots. Therefore, the vegetative growth of the plant decreased at higher density whereas the allocation to reproductive biomass remained constant. This suggests that the annual reproductive effort was positively affected by density. The reproductive output (total reproductive biomass per plant), however, may have decreased with density as a consequence of the density-dependent breakages of shoots at Tjärnö. In contrast to land plants, positive effects of density on reproduction have occasionally been observed in seaweeds (Schiel 1985, Lazo \& Chapman 1998). In these cases growth also increased at higher densities and both effects were correlated. Plants of $A$. nodosum reaching larger sizes have higher reproductive output and annual reproductive effort (Åberg 1996). Since we observed a reduction on the net growth of $A$. nodosum at higher densities, a negative impact of density on reproduction may be expected in successive reproductive periods.

Survival of Ascophyllum nodosum was relatively high and apparently density-independent in both areas. However, the time of the experiment may have been too short to detect any effects on survival. Small adult plants growing beneath the canopy may suffer from a reduction in light but still survive for years before they eventually die. On the other hand, similar results have been observed in other studies of density 
dependence in macroalgae (Black 1974, Reed 1990, Creed et al. 1996). Self-thinning in marine algae occurred mainly among small recruits (Black 1974, Dean et al. 1989, Ang 1991). Certainly, mortality of $A$. nodosum germlings under an adult canopy increased at higher germling density (Viejo et al. 1999). Furthermore, in terrestrial clonal plants low mortality after establishment appears common (Callaghan et al. 1990, de Kroon et al. 1992, Humphrey \& Pyke 1998), and self-thinning and overpopulation may be avoided by achieving a balance in module density (Pytelka 1984). Similar mechanisms may take place in modular seaweeds such as $A$. nodosum. The regulation of module production and growth may also explain the absence of self-thinning that was observed in clonal red seaweeds (e.g., Scrosati 1996).

It may be argued that in this study the buffer zone of the experimental plots was rather small in relation to the size of the plants and, hence, edge effects may have been substantial, especially at low tide. This would complicate the interpretations if non-significant results were obtained. However, our results clearly show a negative effect of density on the net growth of Ascophyllum nodosum. This study and previous work on intertidal macroalgal populations (Ang \& De Wreede 1992, Creed et al. 1996, Creed et al. 1998) indicate that intraspecific competition can occur in the marine shallow environment and not only in populations of deep waters (see comments of Dean et al. 1989, Reed 1990). Our results, however, are in contrast to those of Lazo \& Chapman (1998), who found that high density promoted faster shoot elongation in $A$. nodosum. The presence of both positive and negative density-dependent effects in the same species may be related to interactions with the physical environment. In intertidal habitats the effect of intraspecific interactions in a species can be reversed through the vertical gradient of physical stress (Bertness \& Leonard 1997).

In our study, some differences were detected in density-dependent regulation between the areas investigated. The inception of new shoots was observed only on the Isle of Man and the probability of breakage to smaller sizes (mostly in large plants) was densitydependent only at Tjärnö. The harsher physical conditions in the Swedish area, mainly during winter, may cause this variation in the susceptibility of plant breakage. Although qualitative and quantitative differences in the grazing assemblages were also observed between Tjärnö and the Isle of Man, the density of grazing marks in the plants did not differ between these areas (R.M.V. unpubl. data). This suggests that the differences in the risk of abrasion presumably are not caused by variations in grazing intensity between areas. As consequence of the differences in the density- dependent regulation between Tjärnö and the Isle of Man, plants growing at similar densities may reach larger sizes on the Isle of Man, being longer (because of a lower risk for breakage) and with larger diameter (with a higher number of primary shoots) than at Tjärnö. In a previous work, the mean length of Ascophyllum nodosum plants was found to be higher on the Isle of Man than at Tjärnö (Åberg \& Pavia 1997).

Furthermore, the significance of density-dependent regulation in the dynamics of Ascophyllum nodosum populations probably varies between the studied areas because of their different variability in physical conditions. The environment at Tjärnö can be described as stochastically variable (Åberg 1992b) whereas on the Isle of Man physical conditions are less variable between and within years (see 'Materials and methods'). The demography of $A$. nodosum in the stochastic environment of Swedish shores has been assessed by model simulations (Åberg 1992b). The simulations did not explicitly include density-dependent regulation and it has, in general, seldom been incorporated into demographic models of macroalgae and other perennial plants such as trees (see Burgman \& Gerard 1990, Alvarez-Buylla 1994, Silva Matos et al. 1999). One probable cause for this absence is a lack of knowledge of how the vital rates of different stages are affected by changes in density. However, the present study together with one other (Viejo et al. 1999) also provides data for inclusion of density dependence into demographic models of $A$. nodosum, which would allow evaluation of the importance of density dependence in different physical domains and more realistic projections of the population behaviour.

Acknowledgements. We thank 3 anonymous reviewers for their valuable comments, and all the people at Tjärnö and Port Erin Marine Laboratories for their help and support. This study was funded in part by the EU MASTIII project BIOGAP (MAS3-CT95-0019) and a grant from Kapten C. Stenholms Donationsfond. Rosa Viejo held a postdoctoral fellowship from the Spanish Ministry of Culture and Education.

\section{LITERATURE CITED}

Åberg P (1989) Distinguishing between genetic individuals in Ascophyllum nodosum on the Swedish west coast. Br Phycol J 24:183-190

Åberg P (1990) Measuring size and choosing category size for a transitio Ascophyllum nodosum. Mar Ecol Prog Ser 64: 281-287

Åberg P (1992a) A demographic study of two populations of the seaweed Ascophyllum nodosum. Ecology 73: 1473-1487

Åberg P (1992b) Size-based demography of the seaweed Ascophyllum nodosum in stochastic environments. Eco$\operatorname{logy} 73: 1488-1501$

Åberg P (1996) Patterns of reproductive effort in the brown alga Ascophyllum nodosum. Mar Ecol Prog Ser 138: 199-207 
Åberg P, Pavia H (1997) Temporal and multiple scale spatial variation in juvenile and adult abundance of the brown alga Ascophyllum nodosum. Mar Ecol Prog Ser 158: 111-119

Alvarez-Buylla ER (1994) Density dependence and patch dynamics in tropical rain forest: matrix models and applications to a tree species. Am Nat 143:155-191

Andrew NL, Viejo RM (1998) Effects of wave exposure and intraspecific density on the growth and survivorship of Sargassum muticum (Sargassaceae: Phaeophyta). Eur J Phycol 33:251-258

Ang PO (1991) Natural dynamics of a Fucus distichus (Phaeophyceae, Fucales) population: reproduction and recruitment. Mar Ecol Prog Ser 78:71-85

Ang PO, De Wreede RE (1992) Density-dependence in a population of Fucus distichus. Mar Ecol Prog Ser 90:169-181

Antonovics J, Levin DA (1980) The ecological and genetic consequences of density-dependent regulation in plants. Ann Rev Ecol Syst 11:411-452

Bertness MD, Leonard GH (1997) The role of positive interactions in communities: lessons from intertidal habitats. Ecology 78:1976-1989

Black R (1974) Some biological interactions affecting intertidal populations of the kelp Egregia laevigata. Mar Biol 28:189-198.

Burgman MA, Gerard VA (1990) A stage-structured stochastic population model for the giant kelp Macrocystis pyrifera. Mar Biol 105:15-23

Callaghan TV, Svensson BM, Bowman H, Lindley DK, Carlsson BÅ (1990) Models of clonal plant growth based on population dynamics and architecture. Oikos 57:257-269

Cousens R (1985) Frond size distributions and the effects of the algal canopy on the behaviour of Ascophyllum nodosum (L.) Le Jolis. J Exp Mar Biol Ecol 92:231-249

Cousens R, Hutchings MJ (1983) The relationship between density and mean frond weight in monospecific seaweed stands. Nature 301:240-241

Creed JC, Norton TA, Kain JM (1996) Are neighbours harmful or helpful in Fucus vesiculosus populations? Mar Ecol Prog Ser 133:191-201

Creed JC, Kain JM, Norton TA (1998). An experimental evaluation of density and plant size in two large brown seaweeds. J Phycol 34:39-52

de Kroon H, Hara T, Kwant R. (1992) Size hierarchies of shoots and clones in clonal herb monocultures: do clonal and non-clonal plants compete differently? Oikos 63: 410-419

Dean TA, Thies K, Lagos S (1989) Survival of juvenile giant kelp: the effects of demographic factors, competitors and grazers. Ecology 70:483-495

Fowler NL (1986) Density-dependent population regulation in a Texas grassland. Ecology 67:545-554

Fowler NL (1995) Density-dependent demography in two grasses: a five-year study. Ecology 76:2145-2164

Gaylord B, Blanchette CA, Denny MW (1994) Mechanical consequences of size in wave-swept algae. Ecol Monogr 64:287-313

Gunnill FC (1982) Effects of plant size and distribution on the numbers of invertebrate species and individuals inhabiting the brown alga Pelvetia fastigiata. Mar Biol 69: 263-280

Harper JL (1977) Population biology of plants. Academic Press, London.

Hay ME (1981) The functional morphology of turf-forming seaweeds: persistence in stressful marine habitats. Ecology 62:339-350

Hruby T, Norton, TA (1979) Algal colonization on rocky shores in the Firth of Clyde. J Ecol 67:65-77
Holbrook NM, Denny MW, Koehl MAR (1991) Intertidal 'trees': consequences of aggregation on the mechanical and photosynthetic properties of sea-palms Postelsia palmaeformis Ruprecht. J Exp Mar Biol Ecol 146:39-67

Humphrey LD, Pyke DA (1998) Demographic and growth responses of a guerrilla and a phalanx perennial grass in competitive mixtures. J Ecol 86:854-865

Hutchings MJ, de Kroon H (1994) Foraging in plants: the role of morphological plasticity in resource acquisition. Adv Ecol Res 25:159-238

Johannesson K (1989) The bare zone of Swedish rocky shores: why is it there. Oikos 54:77-86

Jurik TW (1991) Population distributions of plant size and light environment of giant ragweed (Ambrosia trifida L.) at three densities. Oecologia 87:539-550

Kendrik GE (1994) Effects of propagule settlement density and adult canopy on survival of recruits of Sargassum spp. (Sargassaceae: Phaeophyta). Mar Ecol Prog Ser 103: 129-140

Lazo ML, Chapman ARO (1998) Components of crowding in a modular seaweed: sorting through the contradictions. Mar Ecol Prog Ser 174:257-267

Lobban CS, Harrison PJ, Duncan MJ (1985) Physiological ecology of seaweeds. Cambridge University Press, Cambridge

Lovett Doust L (1981) Population dynamics and local specialization in a clonal perennial (Ranunculus repens). I. The dynamics of ramets in contrasting habitats. J Ecol 69: 743-755

Moore PG, Seed R (1985) The ecology of rocky coasts. Hodder \& Stoughton, London

Pavia H, Toth G (2000) Inducible chemical resistance to herbivory in the brown seaweed Ascophyllum nodosum. Ecology 81:3212-3225

Pavia H, Toth G, Åberg P (1999) Trade-offs between growth and phlorotannin production in the brown seaweed AsCophyllum nodosum. J Ecol 87:761-771

Pytelka LF (1984) Application of the $-3 / 2$ power law to clonal herbs. Am Nat 123:442-449

Reed DC (1990) An experimental evaluation of density dependence in a subtidal algal population. Ecology 71: 2286-2296

Rice KJ (1990) Reproductive hierarchies in Erodium: effects of variation in plant density and rainfall distribution. Ecology 71:1316-1322

Schiel DR (1985) Growth, survival and reproduction of two species of marine algae at different densities in natural stands. J Ecol 73:199-217

Schiel DR, Choat JH (1980) Effects of density on monospecific stands of marine algae. Nature 285:324-326

Schmid B (1990) Some ecological and evolutionary consequences of modular organization and clonal growth in plants Evol Trends Plants 41:25-34

Schmid B, Harper JL (1985) Clonal growth in grassland perennials. I. Density and pattern-dependent competition between plants with different growth forms. J Ecol 73: 793-808

Schmitt J, Eccleston J, Ehrhardt DW (1987) Dominance and suppression in experimental radish population. J Ecol 75: 651-665

Schmitt J, Ehrhardt DW, Cheo M (1986) Light-dependent dominance and suppression in experimental radish population. Ecology 67:1502-1507

Scrosati R (1996) The relationship between stand biomass and frond density in the clonal alga Mazzaella cornucopiae (Rhodophyta, Gigartinaceae). Hydrobiologia 326/327: 259-265

Shaw RG (1987) Density-dependence in Salvia lyrata: experi- 
mental alteration of densities of established plants. J Ecol 25:1049-1063

Shaw RG, Mitchell-Olds T (1993) ANOVA for unbalanced data: an overview. Ecology 74:1638-1645

Silva Matos DM, Freckleton RP, Watkinson AR (1999) The role of density dependence in the population dynamics of a tropical palm. Ecology 80:2635-2650

Silvertown JW, Lovett Doust J (1983) Introduction to plant population biology. Blackwell Scientific, Oxford

Sjøtun K, Fredriksen S. (1995) Growth allocation in Laminaria hyperborea (Laminariales, Phaeophyceae) in relation to age and wave expousure. Mar Ecol Prog Ser 126:213-222

Sjøtun K, Fredriksen S, Rueness J (1998) Effect of canopy biomass and wave exposure on growth in Laminaria hyperborea (Laminariaceae: Phaeophyta). Eur J Phycol 33: 337-343

Sorrensen-Cothern KA, Ford ED, Sprugel DG (1993) A model

Editorial responsibility: Otto Kinne (Editor),

Oldendorf/Luhe, Germany of competition incorporating plasticity through modular foliage and crown development. Ecol Monogr 63:277-304

Sprugel DG, Hinckley TM, Schaap W (1991) The theory and practice of branch autonomy. Ann Rev Ecol Sys 22: 309-334

Viejo RM, Åberg P, Cervin G, Lindegarth M (1999) The interactive effects of adult canopy, germling density and grazing on germling survival of the rockweed Ascophyllum nodosum. Mar Ecol Prog Ser 187:113-120

Winer BJ, Brown DR, Michels KM (1991) Statistical principles in experimental design. McGraw-Hill, New York

Weiner J, Thomas SC (1986) Size variability and competition in plant monocultures. Oikos 47:211-222

Westoby M, Howell J (1986) Influence of population structure on self-thinning of plant populations. J Ecol 74:343-359

Yastrebov AB (1996) Different types of heterogeneity and plant competition in monospecific stands. Oikos 75:89-97

Submitted: September 18, 2000; Accepted: January 25, 2001 Proofs received from author(s): September 27, 2001 